\title{
EXISTENCE AND UNIQUENESS SOLUTIONS FOR
}

\section{A CLASS OF HEMIVARIATIONAL INEQUALITIES}

\author{
Ayed E. HashoOsh
}

Abstract. This paper deals with the existence and uniqueness of results for a class of hemivariational inequality problem.

$$
\beta_{1}(x, y)+\beta_{2}(x, y)+J^{0}(x ; y-x) \geqslant 0 .
$$

Moreover, we enhance the main results an application to the existence of solution for a differential inclusion.

Mathematics subject classification (2010): 47H04, 47H05, 47J20, 49J53, 26D15.

Keywords and phrases: Hemivariatinal inequality, monotone bifunction, fixed point theorem, differential inclusion.

\section{REFERENCES}

[1] B. Alleche, V. RǍdulescu, M. Sebaoui, The Tikhonov regularization for equilibrium problems and applications to quasi-hemivariationalinequalities, Optim., 9 (2015) 483-503.

[2] I. ANDREI AND N. CosteA, Nonlinear hemivariational inequalities and applications to nonsmooth mechanics, Adv. Nonlinear Var. Inequal. 13 (2010) 1-17.

[3] J. P. AUBIN, AND F. H. Clarke, Shadow prices and duality for a class of optimal control problems, SIAM J. Control Optim. 17 (1979) 567-586.

[4] M. Berger, Nonlinearity and Functional Analysis, Academic Press, New York(1977).

[5] E. Blum AND W. OetTli, From optimization and variational inequalities to equilibrium problems, The Mathematics Student 63 (1994) 123-145.

[6] H. BREZIS, Analyse Fonctionnelle: Théorie et Applications, Masson, Paris (1992).

[7] F. E. BRowder, The solvability of non-linear functional equations, Duke Math. J. 30 (1963) 557566.

[8] F. H. Clarke, Optimization and Nonsmooth Analysis, Wiley (1983).

[9] N. COSTEA AND V. RǍDULESCU, Existence results for hemivariational inequalities involving relaxed $\eta-\alpha$ monotone mappings, Commun. Appl. Anal. 13 (2009) 293-304.

[10] K. FAN, A generalization of Tychonoffs fixed point theorem, Math. Ann. 142 (1961) 305-310.

[11] Y. P. FANG AND N. J. HuANG, Variational-like inequalities with generalized monotone mappings in Banach spaces, J. Optim. Theory Appl. 118 (2003) 327-338.

[12] P. HARTMAN AND G. STAMPACCHIA, On some nonlinear elliptic differential functional equations, Acta Math. 115 (1966) 271-310.

[13] A. E. Hashoosh and M. Alimohammady, On Well-Posed of Generalized Equilibrium Problems Involving $\alpha$-Monotone Bifunction, Journal of Hyperstructures 5 (2016), 151-168.

[14] A. E. Hashoosh, M. Alimohammady and M. K. Kalleji, Existence Results for Some Equilibrium Problems involving $\alpha$-Monotone Bifunction, International Journal of Mathematics and Mathematical Sciences, 2016 (2016) 1-5.

[15] U. KAMRAKSA AND R. WANGKEEREE, Generalized equilibrium problems and fixed point problems for nonexpansive semigroups in Hilbert spaces, Journal of Global Optimization, 51 (2011) 689-714.

[16] B. Knaster, K. Kuratowski And S. Mazurkiewicz, Ein Beweis des Fixpunktsatzes fur ndimensionale Simplexe, Fund. Math. 14 (1929) 132-137. 
[17] N. K. MAHATO AND C. NAHAK, Mixed equilibrium problems with relaxed $\alpha$-monotone mapping in Banach spaces, Rendiconti del Circolo Matematico di Palermo, (2013).

[18] D. Motreanu, P. D. Panagiotopoulos, Minimax theorems and qualitative properties of the solutions of hemivariational inequalities, Nonconvex Optimization and its Applications 29, Kluwer Academic Publishers, Dordrecht, 1999.

[19] D. MotreAnu, V. RǍDUlescu, Variational and non-variational methods in nonlinear analysis and boundary value problems, Nonconvex Optimization and its Applications 67, Kluwer Academic Publishers, Dordrecht, 2003.

[20] Z. NANiewicz, P. D. PAnagiotopoulos, Mathematical theory of hemivariational inequalities and applications, Monographs and Textbooks in Pure and Applied Mathematics 188, Marcel Dekker, Inc., New York, 1995.

[21] P. D. Panagiotopoulos, Nonconvex energy functions. Hemivariational inequalities and substationarity principles, Acta Mech. 42 (1983) 160-183.

[22] P. D. Panagiotopoulos, M. R. Fundo ANd V. RǍdulescu, Existence theorems of HartmanStampacchia type for hemivariational inequalities and applications, J. Global Optim. 15 (1999) 4154.

[23] J. W. Peng And J. YaO, A viscosity approximation scheme for system of equilibrium problems,nonexpansive mappings and monotone mappings, Nonlinear Anal. 71 (2009) 6001-6010.

[24] V. RǍDULESCU, D. REPOVš, Existence results for variational-hemivariational problems with lack of convexity, Nonlinear Anal. 73 (2010) 99-104.

[25] V. RǍdulescu, D. Repovs, Partial Differential Equations with Variable Exponents: Variational Methods and Qualitative Analysis, CRC Press, Taylor Francis Group, Boca Raton FL (2015).

[26] D. REPOVŠ AND C. VARGA, A Nash type solutions for hemivariational inequality systems, Nonlinear Analysis 74 (2011), 5585-5590.

[27] A. TADA AND W. TAKAHASHI, Weak and strong convergence theorems for a nonexpansive mapping and equilibrium problem, J. Optim. Theory Appl. 133 (2007) 359-370.

[28] E. TARAFDAR, A fixed point theorem equivalent to the Fan-Knaster-Kuratowski-Mazurkiewicz. Theorem, J. Math. Anal. Appl. 2 (1987) 475-479.

[29] R. U. Verma, A-monotonicity and its role in nonlinear variational inclusions, J. Optim. Theory Appl. 129 (2006) 457-467.

[30] R. U. VERMA, On generalized variational inequalities involving relaxed Lipschitz and relaxed monotone operators, Journal of Mathematical Analysis and Applications, 213 (1997) 387-392.

[31] R. U. Verma, On monotone nonlinear variational inequality problems, Commentationes Mathematicae Universitatis Carolinae, 39 (1998) 91-98. 